\title{
APOIO RESPIRATÓRIO NA VOZ CANTADA: PERSPECTIVA DE PROFESSORES DE CANTO E FONOAUDIÓLOGOS
}

\author{
Support and singing voice: perspective of singing teachers \\ and speech language pathologists
}

\author{
Wilson Gava Júnior (1), Leslie Piccolotto Ferreira ${ }^{(2)}$, Marta Assumpção de Andrada e Silva ${ }^{(3)}$
}

\begin{abstract}
RESUMO
Objetivo: analisar a definição de apoio respiratório, assim como as estratégias de trabalho e benefícios de sua aplicação, segundo a perspectiva de professores de canto e fonoaudiólogos. Métodos: seis profissionais com experiência em voz cantada foram entrevistados sobre questões relacionadas ao apoio respiratório no canto. As respostas foram submetidas à análise de conteúdo e definidas quatro categorias: definição de apoio respiratório, tipo de apoio, estratégias e benefícios. Resultados: os aspectos mais mencionados pelos entrevistados foram: a definição de apoio está relacionada com a participação do músculo diafragma e dos intercostais; o tipo de apoio mais adequado é o intercostal e diafragmático; dentre as estratégias de trabalho, utilizadas para a adequação do apoio respiratório, as mais citadas foram propriocepção corporal, conscientização da musculatura envolvida, equilíbrio do fluxo aéreo, alívio de tensões e correção da postura. Há discrepâncias com relação à utilização da contração abdominal, do uso de objetos de apoio, de imagens mentais e realização de vocalizes. Para os entrevistados, o maior benefício do apoio respiratório está no alívio das tensões laríngeas e melhoria na coordenação pneumofonoarticulatória. Houve pouca concordância sobre a ação benéfica do apoio, principalmente quanto à sua melhoria na emissão cantada. Conclusão: os resultados apontam para uma convergência da maioria dos entrevistados quanto à definição, estratégias de trabalho e benefícios do apoio respiratório, porém ainda sem consenso.
\end{abstract}

DESCRITORES: Voz; Exercícios Respiratórios; Diafragma; Treinamento da Voz; Qualidade da Voz

(1) Professor de Canto com Especialização em Fonoaudiologia pela Pontifícia Universidade Católica de São Paulo; Biólogo pela PUCCAMP; Diretor do Studio Gava Cursos Musicais Especializados, Santo André, SP; Diretor da N\&G Artcompany, São Paulo; Professor do Instituto de Canto e Tecnologia de São Paulo; Professor de Canto do Studio Wolf Maya, São Paulo; Preparador Vocal da Oficina de Atores Nilton Travesso, São Paulo; Membro da Sociedade Brasileira de Educação e Integração; Membro da Academia Brasileira de Artes Cultura e História; Mestrando em Fonoaudiologia na Pontifícia Universidade Católica de São Paulo.

(2) Fonoaudióloga formada pela PUC-SP, Mestre em Lingüística Aplicada pela PUC-SP; Doutora em Distúrbios da Comunicação Humana pela UNIFESP-EPM; Professora Titular do Departamento de Fundamentos da Fonoaudiologia e Fisioterapia da PUC-SP (Professora da Faculdade de Fonoaudiologia e do Programa de Estudos Pós-Graduados em Fonoaudiologia); Coordenadora e docente do Curso de Especialização em Fonoaudiologia - Voz; PUC-SP/ COGEAE

(3) Fonoaudióloga; Professora Doutora Assistente do Programa de Estudos Pós-Graduados e do Curso de Graduação em Fonoaudiologia da Pontifícia Universidade Católica de São Paulo - PUCSP; Professora Adjunta do Curso de

\section{INTRODUÇÃO}

No campo da voz cantada em geral o apoio respiratório, support em inglês ou appoggio na tradição italiana, tem sido preconizado por várias gerações de cantores, professores de canto e técnica vocal, com o objetivo de melhorar o controle da emissão vocal.

Graduação em Fonoaudiologia da Faculdade de Ciências Médicas da Santa Casa de São Paulo; Docente nos Cursos de Especialização em Voz do COGEAE-PUC/SP e do CEFAC. Parecerista da Revista Distúrbios da Comunicação, da Revista da Sociedade Brasileira de Fonoaudiologia e da Revista CEFAC; Coordenadora do Ambulatório de Artes Vocais do Departamento de Otorrinolaringologia da Santa Casa e do Curso de Fonoaudiologia da Faculdade de Ciências Médicas da Santa Casa de São Paulo; Mestre em Fonoaudiologia e Doutora em Comunicação e Semiótica pela Pontifícia Universidade Católica de São Paulo.

Conflito de interesses: inexistente 
Cantar é um ato que envolve diversos recursos do aparelho fonador e impõe uma demanda sensivelmente maior quando comparada à fala natural. Para falar e cantar os mesmos órgãos fonoarticulatórios são utilizados, porém, no canto, os ajustes variam de acordo com as exigências impostas pela música e estilo em questão, como, por exemplo, os de sustentação da coluna sonora, os de igualdade tímbrica, de dicção, de fraseado e de interpretação ${ }^{1}$.

Quando se adquire uma melhor condição de respiração e apoio no canto, observa-se maior potência vocal, com uma melhor projeção da voz ${ }^{2}$. A necessidade do aumento dessa potência (loudness) nasceu com a ópera. Segundo registros, foi em 1637, a partir do surgimento da dramaturgia operística italiana, que se deram as primeiras apresentações do denominado Drama Musical. Tais manifestações ocorreram em Veneza, na Itália, e estimularam o aparecimento das primeiras escolas de canto na Europa ${ }^{3}$.

Autores da época do Barroco ressaltavam a importância de se desenvolver um controle respiratório eficiente, porém, em seus textos, não costumavam detalhar sobre como isso deveria ocorrer, de modo que não se sabe se o controle era adquirido pela respiração clavicular, intercostal ou diafragmática ${ }^{4}$.

De tradicional e reconhecida importância, é comum que indivíduos que cantam ou ensinam técnica vocal, atribuam ao apoio respiratório algum tipo de benefício para a voz. Do ponto de vista da percepção, a voz apoiada está diretamente relacionada a um bom controle da emissão vocal ${ }^{5}$. Até mesmo aqueles que atuam com cantores em faixa etária inferior, ou seja, infanto-juvenil, ressaltam que o apoio respiratório, a articulação pneumofonoarticulatória, bem como a afinação, são parâmetros fundamentais nos processos de avaliação fonoaudiológica ${ }^{6}$.

Se por um lado, a importância do apoio respiratório é reconhecida, por outro, seu conceito e aplicação não se mostram tão óbvios. Não há, por exemplo, concordância na utilização de termos ao se referir a um mesmo aspecto.

$\mathrm{Na}$ literatura estudada, por exemplo, afirma-se que o padrão de apoio costodiafragmaticoabdominal é o ideal, por determinar uma fonação mais adequada e proporcionar um melhor equilíbrio na emissão do ar para a voz cantada 7 . Também é feita referência ao diafragma e a musculatura abdominal como de apoio na emissão vocal tanto falada quanto cantada ${ }^{8}$. Outros autores, por sua vez, afirmam que a denominada coluna de ar, responsável pelo apoio, é formada pela musculatura abdominal-diafragmática e/ou intercostal, de modo conjunto ${ }^{9}$.
Segundo a literatura, o apoio denominado inferior contribui para uma voz mais estável, com melhor projeção e controle da hiperfunção laríngea e, para o canto, pode promover uma emissão de voz cantada livre de tensões cervicais. ${ }^{10}$ Pode-se verificar que os cantores que utilizam dos músculos inferiores tais como os abdominais, diafragma e intercostais inferiores adquirem uma emissão mais controlada Em contrapartida, aqueles que trabalham apenas a musculatura intercostal superior (torácica) durante o canto, promovem uma elevação da parte torácica, anteriorização do esterno, tendem a uma captação menor de ar e um aumento das tensões cervicais e laríngeas no ato de cantar.

O conhecimento sobre o funcionamento do sistema respiratório, assim como o domínio técnico sobre ele são alguns dos elementos relevantes para a manutenção do bem estar vocal do profissional da voz ${ }^{11}$. Por esse motivo, os professores de canto realizam exercícios com foco na contração de músculos abdominais ou ainda na precisão articulatória de vogais e consoantes, de modo exaustivo.

Pesquisas mostram que a qualidade vocal e o comportamento respiratório e muscular estão intimamente relacionados ${ }^{12,13}$. A arte do canto exige o controle da respiração e esse é o resultado de um sinergismo de todo o aparelho vocal ${ }^{14} \mathrm{Na}$ mesma direção, pesquisa com cantores profissionais submetidos à preparação vocal evidencia que esses tiveram fluxo aéreo mais adequado à prática do canto, quando comparados aos indivíduos que não se submeteram a tal preparo ${ }^{15}$.

Em trabalho realizado com cantores de coral, autores também apontaram para dificuldades frente à falta de técnica de apoio respiratório. Alertaram que a necessidade de realizar ajustes musculares refinados pode delatar as limitações de habilidades do cantor, fato esse que repercute de modo mais perceptível na voz cantada do que na falada ${ }^{16}$.

Outros estudiosos afirmam que o uso da musculatura costodiafragmáticoabdominal em voz cantada depende diretamente da intenção do som, ou seja, daquilo que se pretende produzir ${ }^{17}$.

$\mathrm{Na}$ literatura referente à voz cantada em geral, comenta-se que o diafragma participa ativamente no modo de inspiração em duas técnicas utilizadas por bons e maus cantores em geral, respectivamente: uma induz ao recolhimento abdominal (belly-in) e outra que emprega a manutenção da expiração torácica (belly-out) ${ }^{18}$. No entanto, estudo que comparou as duas técnicas não encontrou diferenças nos parâmetros vocais ${ }^{19}$.

De modo geral, é evidente que a maioria dos autores concorda em dizer que o apoio respiratório tem sua importância no canto. Contudo, observouse que existem diferenças no entendimento dessa 
importância, uma vez que os estudos sugerem a participação de diferentes músculos na execução desse apoio. Quanto às estratégias utilizadas para adequar o apoio respiratório não está claro na literatura o que tem sido utilizado. Discordâncias relacionadas ao controle da emissão vocal foram observadas até mesmo entre cantores do mesmo gênero musical, de acordo com estudo no qual foram utilizados depoimentos baseados na propriocepção dos participantes ${ }^{20}$.

Independentemente das divergências exemplificadas acima, os autores defendem que o trabalho muscular deve ser estimulado no estudo do canto e das técnicas de apoio. Em uma pesquisa realizada com cantores de coral, constatou-se que a atividade física promove melhorias no desempenho vocal dos participantes, e dentre essas as mais significativas foram dança, expressão corporal e ginástica rítmica. Os resultados obtidos revelaram dificuldades dos cantores para considerar seus corpos como uma unidade mente-físico-emoção. Concluiu-se que o cansaço físico e o mental são de difícil controle, e influenciam no desempenho artístico ${ }^{21}$.

Frente a essas questões que apontam para a necessidade de aprofundar pesquisas sobre o apoio respiratório, o objetivo deste estudo é analisar a definição, as estratégias de trabalho utilizadas e os benefícios destas em relação ao tipo de apoio respiratório para a voz cantada, segundo a perspectiva de professores de canto e fonoaudiólogos.

\section{MÉTODOS}

Foram entrevistados seis profissionais que atuam na área de voz: três professores de canto e três fonoaudiólogos, todos com experiência profissional mínima de três anos em voz cantada, com média de experiência de 16 anos e com idade média de 38 anos de idade. O critério de escolha desses profissionais foi baseado na reconhecida competência no canto, principalmente no conhecimento sobre o canto, tanto no meio científico quanto clínico e/ou na pedagogia vocal. Os entrevistados convidados foram selecionados pelo pesquisador e indicados por sua orientadora por se tratarem de profissionais conhecidos na preparação de cantores, por possuírem publicações científicas em voz cantada, além de fazerem parte de instituições de pesquisa, ou apresentarem vínculos de trabalho com conservatórios musicais de notório renome. Não houve restrição com relação a sexo ou idade dos participantes.

Os participantes foram divididos em dois grupos: no denominado PC foram alocados os professores de canto e no $\mathrm{F}$, os fonoaudiólogos.
O PC foi constituído por sujeitos na faixa etária de 35 e 45 anos, dois do sexo feminino e um do sexo masculino, residentes e atuantes na cidade se São Paulo. Um com experiência profissional de oito anos, o segundo com experiência de 10 anos e o terceiro com experiência de 20 anos. Todos possuem formação superior em música e um deles também especialização em Fonoaudiologia Os focos de atuação desses profissionais são distintos, atingindo um diferente público alvo, considerando população, classes sociais, demandas de interesses, bem como estilo de canto distintos: um segue a linha do canto popular, outro teatro musical, com formação no exterior, e o terceiro atua na preparação de cantores nos gêneros Black Music e Rock.

O grupo $\mathrm{F}$ foi formado por sujeitos na faixa etária de 30 e 45 anos, todos do sexo feminino, atuantes nas cidades de São Paulo e Belo Horizonte. Um, com mestrado e doutorado em Fonoaudiologia, é professor universitário e é autor de diversas publicações sobre o assunto; os outros dois atuam e orientam cantores de coral e artistas de diversos gêneros musicais. Todos especialistas em voz, pertencentes a diferentes grupos científicos. Vale destacar que não há conflito de interesses entre esses profissionais e também não existem dados que revelem um denominador científico em comum, uma vez que não apresentar publicações em conjunto. Quanto à experiência profissional em voz cantada, o primeiro possui mais de vinte anos, o segundo cinco anos e o terceiro dez anos de experiência no trabalho com cantores.

Para a coleta de dados foi realizada entrevista estruturada, aplicada pelo próprio pesquisador do estudo em questão, com três perguntas relacionadas ao apoio respiratório, a saber: defina o que, em sua opinião, vem a ser o apoio respiratório no canto; cite as estratégias utilizadas para que o aluno ou paciente utilize, de modo correto, o apoio respiratório; quais são os benefícios que o apoio respiratório promove.

As entrevistas foram audiogravadas e ocorreram de modo individual, em dias e locais estabelecidos em comum acordo entre o pesquisador e cada um dos entrevistados. Para a gravação foi utilizado um gravador digital marca PANASONIC, modelo RR-US430. As entrevistas foram transcritas em ortografia regular.

Este estudo, de natureza descritiva, foi aprovado pelo Comitê de Ética e Pesquisa da Pontifícia Universidade Católica de São Paulo - PUC-SP, sob o número 301/2008. Obteve-se o Consentimento Livre e Esclarecido por escrito dos participantes da pesquisa. 
A avaliação das entrevistas pautou-se na análise de conteúdo proposta por Bardin em $1977^{22}$. Assim, após sucessivas leituras do material transcrito, as respostas obtidas nas entrevistas foram categorizadas, segundo as convergências e divergências encontradas.

\section{RESULTADOS}

As entrevistas realizadas apresentaram uma média de 11 minutos e 25 segundos, sendo que a duração mínima foi de sete minutos e 34 segundos e a duração máxima, de 15 minutos e 16 segundos.

Com base na recorrência dos aspectos presentes nas respostas dos entrevistados, determinados pelas perguntas realizadas, foi possível definir quatro categorias, que permitiram a organização do material de forma sistemática, e favoreceram a apresentação dos dados. Essa foi feita por meio de quadros sintéticos de cada categoria e recortes da analise de conteúdo para exemplificar. As categorias foram apresentadas nas Figuras de 1 a 4.

A Figura 1 apresenta a distribuição dos sujeitos de acordo com os aspectos mencionados na definição de apoio respiratório. Verifica-se a relação entre o diafragma e a musculatura intercostal citada por todos os entrevistados em suas definições do tema. Os recortes da análise de conteúdo que exemplificam a questão são:

“... o apoio é uma sensação que se tem de um ponto de suspensão do ar... que é feita pelos músculos abdominais mais baixos..." (PC1).

"Tem algumas técnicas que trabalham o diafragma como na respiração da Yoga, empurrando pra baixo. Eu gosto de trabalhar o diafragma junto com a intercostal" (PC2).

"Para uma música ele vai usar a respiração abdominal, para a outra, que exige frases mais longas, ele vai usar o costodiafragmático. Existe também o costodiafragmático abdominal que mexe tanto o abdômen quanto as costelas" (F3). "Então para eu poder apoiar a voz e manter, quando eu estou cantando... devo ter sempre os músculos do baixo abdômen ligeiramente contraídos e o diafragma livre" (F1).

A Figura 2 apresenta as referências feitas pelos entrevistados quanto à nomenclatura utilizada para se referirem ao apoio respiratório na voz cantada. Os principais recortes das análises são exemplificados a seguir:

“... o diafragma é o músculo responsável pela respiração, que também é auxiliada pelos músculos intercostais". (PC3);

\begin{tabular}{|l|c|c|}
\hline DEFINIÇÃO DE APOIO RESPIRATÓRIO & PC & F \\
\hline Está relacionado com o diafragma & $1,2,3$ & $1,2,3$ \\
\hline Está relacionado com músculos Intercostais & $1,2,3$ & $1,2,3$ \\
\hline O apoio respiratório é uma sensação & 1,2 & 1,2 \\
\hline Está relacionado com baixos abdominais contraídos & 1 & $1,2,3$ \\
\hline Está relacionado a um equilíbrio entre forças musculares & 1,3 & \\
\hline Imagem de um ponto de suspensão do ar & 1 & \\
\hline Imagem de um alicerce ou parede de sustentação & 2 & 1 \\
\hline Está relacionado com músculos glúteos & & \\
\hline
\end{tabular}

Figura 1 - Distribuição dos sujeitos (PC - professores de canto; F - fonoaudiólogos) de acordo com os aspectos mencionados na definição de apoio respiratório

\begin{tabular}{|l|c|c|}
\hline NOMENCLATURA DO APOIO & PC & F \\
\hline Intercostal & $1,2,3$ & $1,2,3$ \\
\hline Diafragmático & $1,2,3$ & $1,2,3$ \\
\hline Baixo abdominal & 1 & $1,2,3$ \\
\hline Costodiafragmático-abdominal & - & 1,2 \\
\hline Costodiafragmático & - & 2,3 \\
\hline
\end{tabular}

Figura 2 - Distribuição dos sujeitos (PC - professores de canto; F - fonoaudiólogos) de acordo com a nomenclatura dada ao apoio respiratório 
“... para a outra, que exige frases mais longas, ele vai usar o costodiafragmático... você movimenta o abdômen junto com as costelas." (F2);

"Eu trabalho com a respiração costodiafragmaticoabdominal." (F1)

A Figura 3 representa as estratégias colocadas em prática pelos entrevistados para conseguir o apoio respiratório. Os seguintes trechos ilustram as respostas dos entrevistados:

"Então a primeira coisa que faço é trazer as mãos. Fazer com a pessoa coloque as mãos na parte mais baixa das costelas, na última costela que ela consegue sentir embaixo, pra daí começar a trabalhar a respiração" (PC3);

"Peço, inclusive, para ele fechar os olhos e logo em seguida dou como exemplo a imagem de uma bexiga que infla no baixo abdômen. Ainda sentado, coloco a mão no abdômen do sujeito e a mão dele por cima da minha. À medida que isso (respiração baixa) vai se instalando eu vou corrigindo a postura de queixo e as tensões" (F2).

"Primeiro muitos exercícios de respiração pra que a pessoa sinta. Sinta como fazer para deixar as costelas abertas. Se as costelas estão abaixando, oriento para que ela perceba que tem que aumentar a força de baixo para equilibrar isso. Depois trabalho exercícios com canto." (PC1);

"Abro os músculos intercostais, quero dizer, abro minhas costelas, lateralmente, funcionando como uma sanfona" (F1);

"Deitar no chão e, às vezes, colocar um pequeno peso em cima: um livro, ou alguma coisa assim, no abdômen, pra gente sentir a respiração..." (PC3);

"... eu sempre uso uma vela. Peço pra ele aplicar esse apoio respiratório com uma vela acesa. Com aproximadamente um palmo de distancia dos lábios, peço pra ele soprar a vela fazendo a chama tremer. Não deve apagar. Ele deve coordenar essa saída de ar, sentido que o abdômen está encolhendo." (F3);

"... imagine como se você tivesse um elástico vertical interno e ai, com essa musculatura, você vai empurrando o ar, sem deixar a intercostal relaxada, sempre com a intercostal montada". (PC2);

"É melhor deixar essa parte mais aberta e para o baixo ventre trabalhar." (C1);

"Você não pensa: - Estou respirando, estou apoiando, estou articulando... essas coisas você pensa durante a aula de canto, na correção que o professor faz durante os vocalizes." (C3)

\begin{tabular}{|l|c|c|}
\hline ESTRATÉGIAS & PC & F \\
\hline $\begin{array}{l}\text { Estratégias de estímulo a propriocepção (ampliação da } \\
\text { consciência corporal) }\end{array}$ & $1,2,3$ & $1,2,3$ \\
\hline $\begin{array}{l}\text { Conscientização da participação da musculatura } \\
\text { abdominal e intercostal }\end{array}$ & $1,2,3$ & $1,2,3$ \\
\hline Estratégias para o equilíbrio do fluxo aéreo & $1,2,3$ & $1,2,3$ \\
\hline Alívio de tensões e correção de postura & $1,2,3$ & $1,2,3$ \\
\hline $\begin{array}{l}\text { Estratégias para a manutenção das intercostais abertas na } \\
\text { expiração }\end{array}$ & $1,2,3$ & 1,2 \\
\hline Estratégias com certa contração abdominal & 2 & $1,2,3$ \\
\hline $\begin{array}{l}\text { Objetos como artifícios auxiliares (espelho,livro no } \\
\text { abdômen, vela, bexiga etc.) }\end{array}$ & 3 & $1,2,3$ \\
\hline Exercícios expiratórios com sons fricativos & 2,3 & 2,3 \\
\hline Explicações sobre a fisiologia & 1,3 & 1,2 \\
\hline $\begin{array}{l}\text { Imagens mentais (elástico interno, coluna de ar, bexiga no } \\
\text { abdômen, etc.) }\end{array}$ & 1,2 & - \\
\hline Estratégias com abdome livre & 1,3 & - \\
\hline Vocalizes & 1,3 & \\
\hline
\end{tabular}

Figura 3 - Distribuição dos sujeitos (PC - professores de canto; F - fonoaudiólogos) de acordo com os aspectos mencionados nas estratégias utilizada para o apoio respiratório 
$\mathrm{Na}$ Figura 4 foram reunidos os benefícios do apoio respiratório, segundo os profissionais entrevistados. Como exemplos de relatos dos profissionais, segue:

“... se você não trabalha o apoio respiratório no diafragma esse apoio vem pra garganta e (isso) não é legal." (PC2);

"Para retirar o foco de tensão da região laríngea, cervical e da cintura escapular. Também para ter uma voz mais projetada além de se conseguir uma melhor coordenação pneumofonoarticulatória." (F3);

"Com esse tipo de apoio respiratório eu consigo coordenar melhor a respiração." (F3);

"Eu acho que o apoio interfere na ressonância também. O aparelho funciona muito conjugado e não dá pra separar articulação, emissão e ressonância. Acho que tudo tem influência em tudo." (PC1);

"... eu acho que se fica com uma voz com mais brilho, com uma ressonância mais equilibrada, você tem uma possibilidade de ter uma ressonância mais de acordo com o que você deseja." (F1);

"O ar para o cantor é como o combustível para o carro, se você não se abastece direito, de ar, você não tem como cantar, ou melhor, se você não trabalha o apoio respiratório no diafragma esse apoio vem pra garganta, e não é legal."(C2); "Poupando a voz e estamos falando não só de estética, mas de saúde e longevidade vocal. A gente percebe que os cantores que usam o apoio se beneficiam por esse motivo." (C1)

\begin{tabular}{|l|c|c|}
\hline BENEFíCIOS & PC & F \\
\hline Alívio de tensões laríngeas & $1,2,3$ & $1,2,3$ \\
\hline Maior controle respiratório - pneumofonoarticulatório & $1,2,3$ & 1,3 \\
\hline Melhoria na expressividade - Interpretação & 2,3 & 1,3 \\
\hline Ação benéfica geral e melhoria na emissão cantada & $1,2,3$ & 1 \\
\hline Sustentação de frases & - & $1,2,3$ \\
\hline Melhoria na ressonância & 1 & 1,2 \\
\hline $\begin{array}{l}\text { Recursos relacionados à maior mobilidade do foco vocal } \\
\text { (ressonantal) }\end{array}$ & 2,3 & 1 \\
\hline Melhoria na postura corporal & 2,3 & 3 \\
\hline Ampliação da potência vocal - Loudness & 3 & 3 \\
\hline Aumento da longevidade vocal & 1 & - \\
\hline Melhor condição para vibratos & 1 & - \\
\hline Alívio de tensão escapular e cervical & - & 3 \\
\hline
\end{tabular}

Figura 4 - Distribuição dos sujeitos (PC - professores de canto; F - fonoaudiólogos) de acordo com os aspectos mencionados nos benefícios do apoio respiratório

\section{DISCUSSÃO}

Os dados discutidos serão apresentados inicialmente de acordo com cada grupo - professores de canto e fonoaudiólogos - para explicitar as informações de cada categoria profissional e mostrar sua relação com a literatura estudada.

Entre os dois grupos houve unanimidade na definição de apoio respiratório quanto a este apresentar relação direta com a musculatura do diafragma, bem como a musculatura intercostal. $\mathrm{Na}$ literatura investigada, autores consideram o apoio com participação do diafragma e musculatura intercostal, quando afirmam que o padrão de apoio costodiafragmáticoabdominal é o ideal ${ }^{7,10}$. Faz-se referência ao diafragma e à musculatura abdominal como de apoio na emissão vocal, tanto na voz falada quanto cantada ${ }^{8}$. Outros estudos, por sua vez, afirmam que o apoio respiratório é formado pela musculatura abdominal-diafragmática e/ou intercostal de modo conjunto ${ }^{9}$. O segundo aspecto mais comentado entre os dois grupos foi o fato de o apoio respiratório tratar-se de uma sensação (dois professores de canto e dois fonoaudiólogos). Um dos professores de canto valoriza o fato de tal apoio ter função de sustentação da voz, faz analogias a um alicerce ou parede e preconiza a participação do diafragma com a abertura lateral das 
costelas. Tal definição apresenta suporte na literatura, uma vez que é possível encontrar estudos que definem o apoio como uma sensação que os cantores tem durante o canto ${ }^{23}$. Ao se considerar o termo sensação pode-se aludir à percepção dos sons, ou ações musculares, que o cantor deve ter no próprio corpo, ou seja, a propriocepção. Na literatura vários autores valorizam o trabalho proprioceptivo, tanto no processo de aprendizagem do canto quanto para se obter bons resultados no uso da voz em geral 5,7,10,17. Tais autores afirmam que, do ponto de vista da percepção, a voz apoiada está diretamente relacionada à boa voz. Uma das pesquisas ${ }^{5}$ evidencia tal relação ao analisar amostras de sílabas cantadas por cantores profissionais com e sem apoio respiratório. Juízes com e sem experiência em canto, ao ouvirem as amostras, associaram os trechos com apoio à emissão mais estável na voz cantada. Em estudo realizado com cantores amadores e profissionais, os depoimentos analisados foram baseados na propriocepção dos participantes ${ }^{20}$. Vale destacar que o professor de canto PC2 não utilizou o termo sensação, porém tal conceito apareceu de modo subjetivo no discurso quando o mesmo afirmou utilizar estratégias de propriocepção em sua conceituação de apoio respiratório. Uma fonoaudióloga, por sua vez, quando questionada sobre o apoio respiratório, iniciou o discurso com a classificação do tipo de apoio e se estendeu com a explicação das estratégias e benefícios promovidos pelo apoio respiratório.

Houve disparidade de conceitos entre os grupos quando, na definição de apoio respiratório, foi considerada a contração dos músculos da região mais baixa do abdome, tais como os músculos do assoalho pélvico, inclusive o diafragma. Todos os fonoaudiólogos consideraram esse aspecto enquanto apenas por um professor de canto (PC1) o incluiu em suas considerações. Dois fonoaudiólogos consideraram a expansão da região baixa do abdome de modo enfático. O que se apresenta em concordância com a literatura ${ }^{10}$, quando a autora afirma que "o apoio, também denominado inferior contribui para uma voz mais estável, com melhor projeção e controle da hiperfunção laríngea". Em outra pesquisa, autora afirma que são elementos relevantes para a manutenção da saúde do profissional da voz a realização de exercícios com foco na contração de músculos abdominais ${ }^{10}$ e também é referido que se deva, durante o canto, manter o recolhimento abdominal (belly-in) ${ }^{18}$.

Ainda dentre os aspectos menos abordados entre todos os entrevistados estão às definições que referem o Apoio Respiratório como um equilíbrio entre forças musculares, aludindo ao diafragma, intercostais e músculos da região baixa do abdome (grande oblíquo externo, pequeno oblíquo, transverso abdominal, parte inferior do reto abdominal e diafragma). Menos referidos ainda são os aspectos onde apenas um, entre todos os entrevistados, considerou: ponto de suspensão do ar (PC1), alicerce ou parede de ar (PC2) relação com músculos glúteos (F1), ou seja, não se observou consenso intra ou intergrupos, em relação a tais parâmetros. A literatura faz referência objetiva ao equilíbrio de forças e em estudos recentes, os autores referem que a denominada coluna de ar, responsável pelo apoio, é formada pela musculatura abdominal-diafragmática e/ou intercostal, de modo conjunto 9,14 .

Vale acrescentar que, no momento da entrevista, apesar da característica objetiva da pergunta relacionada à definição de apoio respiratório, os entrevistados, se mostraram hesitantes no modo de responder. Alguns explicaram as estratégias utilizadas para a obtenção do apoio, outros iniciaram o discurso com a classificação dos tipos de apoio ou mesmo os seus benefícios, sem a objetivação da resposta.

Em relação à nomenclatura do apoio todos os participantes, de ambos os grupos, consideraram que o apoio é intercostal e diafragmático. Todos os fonoaudiólogos e um professor de canto (PC1) ainda consideram a participação ativa da musculatura do baixo abdome. Apenas dois fonoaudiólogos (F1 e F2) denominaram o tipo de apoio respiratório como costodiafragmáticoabdominal, ou apenas costodiafragmático ${ }^{7-10,18}$.

Interessante ressaltar que, em cada um dos grupos, dois dos três profissionais entrevistados não responderam objetivamente à questão. Dessa forma, alguns dos participantes não classificaram de modo imediato o tipo de apoio quando objetivamente questionados, porém apresentaram a classificação ao discorrerem sobre as estratégias. Todos os entrevistados consideraram mais de um grupo muscular quando se referiram ao tipo de apoio respiratório. Um fonoaudiólogo (F1) afirmou que o tipo respiratório é o costodiafragmáticoabdominal, contudo durante a descrição de suas estratégias incluiu a musculatura intercostal.

Todos os fonoaudiólogos também consideraram a participação dos músculos baixo-abdominais e apenas um professor de canto (PC1) considerou tal aspecto.

Observou-se que os três fonoaudiólogos fizeram referência ao tipo de apoio respiratório como costodiafragmático ou costodiafragmáticoabdominal, enquanto que os professores de canto não utilizaram essa nomenclatura, o que pode indicar que tais termos sejam mais empregados por fonoaudiólogos. F2 e F3 afirmaram que o apoio é 
costodiafragmático com a participação das intercostais e um deles ainda comentou que o apoio do tipo baixo abdominal é o mais eficaz para o canto. O profissional explicou que, em algumas situações, o apoio deve mudar para costodiafragmáticoabdominal, e tal mudança depende do estilo musical em questão. Essa abordagem corrobora com alguns estudos existentes que também enfatizam esse tipo de apoio ${ }^{7-10,18}$.

A utilização de diferentes estruturas para se atingir o apoio respiratório mais adequado foi observada também em estudo que investigou a consistência do comportamento respiratório durante o canto. Foi observado que os participantes realizaram movimentos variados de caixa torácica e do abdome para atingir um volume pulmonar durante os trechos cantados, mostrando que não ocorreu, entre os cantores, uma estratégia de respiração uniforme ${ }^{24}$.

$\mathrm{Na}$ terceira categoria denominada estratégias para o apoio no canto, houve unanimidade entre todos os entrevistados em relação às estratégias de estímulo à propriocepção, participação da musculatura abdominal e intercostal, equilíbrio do fluxo aéreo, alívio das tensões e correção de postura.

Com relação às estratégias de estimulo à propriocepção, F2 detalha a aplicação de exercícios com sons surdos, enquanto utiliza recursos táteis para a identificação do tipo respiratório. Comenta que coloca tanto a sua própria mão quanto a do cantor sobre o abdômen do mesmo. Mantém o paciente sentado e orienta a postura do queixo e alívio das tensões. PC2 e PC3 orientam a propriocepção do diafragma com a ajuda das mãos na parte inferior das costelas. PC3 explica que enquanto se inspira, deve-se observar a expansão lateral da parte baixa do abdômen e, com isso, se evitar a elevação torácica. Sob esse aspecto encontram-se referências na literatura em diversos trabalhos ${ }^{7-10,18}$.

Ao utilizar a participação da musculatura abdominal e intercostal como estratégia para se conseguir o apoio respiratório, um fonoaudiólogo preconiza que o abdômen deve estar levemente contraído. Um professor de canto orienta a expansão do baixo abdômen durante o processo de inspiração e um fonoaudiólogo, além dos músculos abdominais, diafragma e intercostais, explica que o apoio respiratório vem da região baixa da coluna e é auxiliado pela participação da musculatura glútea. A diferença nas estratégias realizadas indica também uma distinção entre os profissionais com relação ao padrão de apoio respiratório que preconizam. $\mathrm{Na}$ literatura, tais diferenças também aparecem. Alguns autores afirmam que o padrão de apoio costodiafragmáticoabdominal é o ideal ${ }^{6}$; outros fazem referência ao diafragma e a musculatura abdominal ${ }^{8}$; comenta-se que o diafragma participa ativamente no modo de inspiração em duas técnicas uma induz ao recolhimento abdominal e outra que emprega a manutenção da expiração torácica ${ }^{18}$. Refere-se também que o apoio denominado inferior contribui para uma voz mais estável ${ }^{10}$.

Sobre a correção de postura, um fonoaudiólogo alerta sobre a importância do "encaixe da pelve" e da criação de um eixo corporal para facilitar o apoio. Investiga a ergonomia do paciente inclusive durante o sono. Tal preocupação com a postura pode ser verificada também na literatura ${ }^{10,17}$.

Em relação ao controle do fluxo aéreo deve-se destacar que esse talvez seja 0 aspecto que aparece de forma mais recorrente na tradição do ensino. Estudo revela que autores da época do Barroco ressaltavam a importância de se desenvolver um controle respiratório eficiente ${ }^{4}$. Um fonoaudiólogo explicou que, com o objetivo de melhorar o controle do fluxo aéreo, utiliza uma vela acesa. Mantém a mesma a um palmo de distância dos lábios do paciente e o orienta a manter um fluxo de ar constante, de modo que a chama não se apague. $\mathrm{Na}$ literatura, afirma-se que a arte do canto exige o controle da respiração e esse é o resultado de um sinergismo conquistado por todo o aparelho vocal ${ }^{14}$. Em pesquisa realizada com cantores profissionais submetidos à preparação vocal, esses tiveram fluxo aéreo mais adequado à prática do canto, quando comparados aos indivíduos que não se submeteram a tal preparo ${ }^{15}$.

O segundo aspecto mais concordante entre os grupos (cinco entrevistados - todos os professores de canto e dois fonoaudiólogos) relacionou-se com a utilização de estratégias para a manutenção dos intercostais expandidos na expiração. Um dos participantes detalha que aplica exercícios de respiração com foco na expansão e manutenção da musculatura intercostal, além da contração do abdômen, de modo a equilibrar as duas forças. $\mathrm{Na}$ sequência trabalha vocalizes para a voz cantada e uma música é aplicada de modo que o apoio respiratório se estabilize. Ainda, como estratégia, solicita que o aluno cante, e mantenha a postura anterior, com a abertura e sustentação da musculatura intercostal, para melhor controle do fluxo aéreo. Justifica que as costelas são mantidas abertas para o não fechamento da musculatura abdominal, para que se evite a constrição laríngea e conseqüente perda de qualidade na emissão vocal. Esse profissional utiliza o termo "coluna de ar" ao se referir ao apoio respiratório e foca em seu discurso a importância de não haver excesso de pressão. Citações relacionais a esse tipo respiratório são encontradas outros trabalhos ${ }^{7-10,14,17 .}$. 
Estratégias que se utilizam de certa contração abdominal foi um aspecto considerado por todos os fonoaudiólogos e por apenas um professor de canto. Um professor de canto afirma que orienta a modulação sonora, do grave para o agudo, e estimula a contração abdominal de modo lento. Na literatura, faz-se referência ao diafragma e a musculatura abdominal como de apoio na emissão vocal ${ }^{8}$. Outras pesquisas também consideram a musculatura abdominal para a obtenção do apoio respiratório $7,9,10,17$.

A utilização de objetos como artifícios para explicar o apoio respiratório também representou uma estratégia empregada por quatro dos entrevistados ( todos os fonoaudiólogos e apenas um professor de canto). Para citar um exemplo, esteve presente no discurso de dois fonoaudiólogos a utilização de balões de festas, como estratégia. Um deles detalha que com o balão cheio, colocado entre o abdome do paciente e uma parede, solicita ao mesmo que realize uma inspiração abdominal. Pede que esse observe a compressão do balão de festas. Explica que para a percepção da expansão das intercostais, muda a posição do balão. Com o paciente de perfil, posiciona o balão entre a parede e as intercostais de ambos os lados. Um professor de canto explica que como estratégia, comenta que também utiliza a colocação de um livro na região abdominal; com o aluno na posição deitado, com foco na ampliação da consciência respiratória. Conclui suas orientações com a conscientização do aluno para a importância do treinamento dos exercícios, diariamente, para que a técnica seja incorporada. Ressalta-se que, na literatura, é encontrado registro de utilização de objetos como artifício para realizar o tipo e não o apoio respiratório.

Quatro entrevistados (dois professores de canto e dois fonoaudiólogos) incluíram explicações sobre conceitos fisiológicos nas descrições de suas estratégias. Na literatura, a utilização desses conceitos na execução das estratégias é muito comum entre os autores. Mais quatro profissionais, dois professores de canto e dois fonoaudiólogos, referiram exercícios expiratórios com sons fricativos como estratégias para o apoio respiratório. Um dos fonoaudiólogos explica que como parte de suas estratégias aplica exercícios de emissão de /s/, /z/ e /f/ sustentado, do mesmo modo que outro fonoaudiólogo e dois professores de canto. Esses dois professores de canto salientaram que, durante suas explicações orientam sobre a necessidade de manter expandida da região baixa do abdome durante os exercícios expiratórios com sons fricativos, com o objetivo de desenvolver um maior controle do fluxo aéreo. Um explica que enquanto se inspira, deve-se observar a expansão lateral da parte inferior do abdome e, com isso, evitar a elevação torácica ${ }^{7,10}$.

Dentre os aspectos menos referidos pode-se considerar imagens mentais, estratégias com o abdome livre e vocalizes que foram considerados apenas por dois professores de canto e nenhum fonoaudiólogo. Apesar da pouca referência nessa pesquisa, observa-se que estratégias com 0 abdome livre são referidas na literatura ${ }^{9}$. Quanto às estratégias de imagens mentais e vocalizes, sabe-se que seu uso é difundido na área do ensino de canto, porém não foi encontrada referência na literatura pesquisada.

Quanto aos benefícios do apoio respiratório houve unanimidade entre todos os entrevistados em relação ao alívio das tensões laríngeas. Um professor de canto comenta que o apoio respiratório promove o alivio das tensões laríngeas e que isso além da melhoria na qualidade estética da voz beneficia a saúde e a longevidade vocal. Um dos fonoaudiólogos entrevistados explica que com o apoio respiratório conquista-se um maior domínio geral da voz. O trato vocal se mantém mais aberto e isso alivia as tensões laríngeas. Fluxo de ar constante permite frases musicais mais longas. O brilho e a ressonância são beneficiados e uma maior mobilidade de foco vocal. O apoio respiratório contribui para uma voz mais estável, com melhor controle da hiperfunção laríngea ${ }^{10}$.

O segundo aspecto mais apontado pelos entrevistados foi à melhoria no controle respiratório (pneumofonoarticulatório). Todos os professores de canto comentaram tal benefício, bem como duas fonoaudiólogas. Um professor de canto refere como benefício do apoio respiratório o maior equilíbrio de pressão do fluxo aéreo e, com isso, melhor estabilidade na emissão sonora. Na literatura pesquisada, em trabalho com cantores infanto-juvenis, verificouse que o apoio respiratório, a articulação pneumofonoarticulatória, bem como a afinação, são parâmetros fundamentais nos processos de avaliação fonoaudiológica ${ }^{6}$. Uma melhor ventilação pulmonar também é comentada por outros autores ${ }^{7}$. A arte do canto exige o controle da respiração e esse é o resultado de um sinergismo conquistado por todo o aparelho vocal ${ }^{14}$. Em pesquisa com cantores profissionais submetidos à preparação vocal, evidenciase que esses tiveram fluxo aéreo mais adequado à prática do canto, quando comparados aos indivíduos que não se submeteram a tal preparo ${ }^{15}$.

Quatro entrevistados (dois professores de canto e dois fonoaudiólogos) atribuíram ao Apoio Respiratório o benefício da melhoria na interpretação (expressividade), aspecto esse que vai ao encontro da literatura, uma vez que se afirma que os efeitos benéficos de um apoio respiratório adequado podem 
ser constatados fisiológica e musicalmente, por meio das características harmônicas da emissão e equilíbrio dos ajustes do aparelho vocal ${ }^{10}$.

Pouca concordância ocorreu em relação à ação benéfica geral e melhoria na emissão cantada. Tais aspectos foram considerados por todos os professores de canto, mas por apenas um fonoaudiólogo. Na literatura, afirma-se que o uso da musculatura em voz cantada depende diretamente da intenção do som, ou seja, daquilo que se pretende produzir ${ }^{17}$. Outros autores complementam que a participação do que denominam sustentação da coluna sonora (Apoio Respiratório) auxiliam nos ajustes do aparelho fonador que serão realizados segundo as exigências de cada música ${ }^{1}$. Para um dos professores de canto entrevistados, o apoio respiratório permite que os benefícios envolvam todo o aparelho vocal, melhorando o desempenho geral do cantor. Promove ajustes mais corretos na posição da cabeça, entre outros e, com isso, se pode cantar mais relaxado e pode-se direcionar a atenção para outros aspectos no ato de cantar.

Por outro lado, dois fonoaudiólogos afirmam que a melhoria na qualidade ressonantal é um benefício advindo do apoio respiratório, aspecto mencionado apenas por um professor de canto. Três entrevistados (dois professores de canto e um fonoaudiólogo) comentam como benefício do apoio respiratório recursos relacionados à maior mobilidade do foco ressonantal e melhoria na postura corporal.

A ação benéfica geral na voz e melhoria na emissão cantada foi considerada por todos os professores de canto e apenas um fonoaudiólogo, em contrapartida todos os fonoaudiólogos relataram a melhoria na sustentação de frases musicais, curiosamente esse aspecto não foi mencionado por nenhum professor de canto. Interessante observar a pequena ocorrência de respostas referentes a esses aspectos, uma vez que se trata de questões diretamente relacionadas ao canto, porém pouco enfatizadas nas respostas fornecidas.

Aspectos como melhoria na ressonância, melhoria na postura corporal, recursos relacionados à maior mobilidade do foco ressonantal e sustentação de frases foram referidos cada um deles por três, dos seis entrevistados, fato que indica que não há um consenso entre os dois grupos de profissionais quanto aos efeitos do apoio respiratório nesses parâmetros.

Dois profissionais, um professor de canto e um fonoaudiólogo referiram a ampliação da potencia vocal (loudness) ao apoio respiratório. Na literatura, benefícios como o alívio das tensões cervicais, estabilidade na emissão e aumento na projeção da voz, encontram respaldo em dois trabalhos ${ }^{5,10}$. Dentre os aspectos menos relatados, que foram considerados por apenas um, dentre todos os entrevistados, temos: o aumento da longevidade vocal e melhores condições para vibratos, referido por apenas um professor de canto bem como o alívio da tensão escapular e cervical, referido também somente por um fonoaudiólogo.

\section{CONCLUSÃO}

De acordo com a perspectiva dos fonoaudiólogos e professores de canto entrevistados nesta pesquisa, pode-se definir o apoio respiratório como uma propriocepção ou sensação das ações musculares relacionadas ao diafragma e à musculatura intercostal, sendo que os tipos de apoio mais mencionados foram o intercostal e o diafragmático. As estratégias utilizadas para se trabalhar o apoio relacionam-se o estímulo à propriocepção, participação da musculatura abdominal e intercostal, equilíbrio do fluxo aéreo, alívio das tensões e correção de postura. Para os entrevistados, o maior benefício do apoio respiratório está no alívio das tensões laríngeas e melhoria na coordenação pneumofonoarticulatória.

Observou-se que, apesar de haver concordância entre professores de canto e fonoaudiólogos na maioria dos aspectos abordados, os profissionais ainda diferem entre si em aspectos como a nomenclatura utilizada, bem como as estratégias aplicadas para ensino do apoio respiratório. Sugere-se que estudos futuros possam envolver um número maior de profissionais para que essas discordâncias sejam investigadas mais profundamente. 


\section{ABSTRACT}

Purpose: to analyze the definition of breath support, as well as the strategies used to achieve it and their benefits according to both singing teachers and Speech Language Pathologists (SLP). Methods: six professionals experienced in singing voice answered an interview on issues pertaining to singing breath support. The answers were submitted to content analysis from where four categories were derived: definition of breathing support, type of support, strategies and benefits. Results: the aspects that were most often reported by the professionals are: the definition of breath support is related to the participation of the diaphragm and intercostal muscles; the most adequate type of support is intercostal and diaphragmatic; among the strategies used to improve breathing support, the most commonly mentioned were body perception, awareness of the muscles involved in the process, air flow balance, tension relief and posture alignment. There are discrepancies as for the abdominal contraction, use of different objects as guidelines, mental imagery, and use of singing exercises - vocalizes. According to the interviewed subjects, the greatest benefit of breath support lies in the relief of laryngeal tensions and improvement of respiratory coordination. There was a low level of agreement about the benefits of support, especially with regards to the improvement of the singing voice. Conclusion: the results point out to a convergence of opinions as for most of the interviewed subjects when considering the definition, approach strategies and benefits of breathing support, however, still with no consensus on the subject.

KEYWORDS: Voice; Breathing Exercises; Diaphragm; Vocal Training; Voice Quality

\section{REFERÊNCIAS}

1. Andrade SR, Fontoura DR. Inter-relações entre fonoaudiologia e canto. Música Hodie Rev Acad Mus. 2007; 7(1):83-98.

2. Thorpe CW, Cala SJ, Chapman J, Davis, PJ. Patterns of breath support in projection of the singing voice. J Voice. 2001; 15(1):86-104.

3. Costa L. As velhas amas das óperas venezianas seiscentistas: um elo entre o teatro falado e cantado. Per Musi - Rev Acad Mus. 2008; 17:26-31.

4. Fernandes AJ, Kayama AA. A sonoridade vocal e a prática coral no Barroco. Per Musi - Rev Acad Mus. 2008; 18:59-68.

5. Hurme P, Kara K, Laukkanem AM, Sonninem A. Evaluation of support in singing. J Voice. 2005; 19(2):223-37.

6. Souza DPD, Silva ABV, Jarrus ME, Pinho SMR. Avaliação fonoaudiológica vocal em cantores infanto-juvenis. Rev CEFAC. 2006; 8(2):216-22.

7. Ferreira LP, Pontes PAL. Avaliação fonoaudiológica da voz: o valor discriminatório das provas respiratórias. In: Ferreira LP. Um pouco de nós sobre voz. São Paulo: Pró Fono; 1995. p 1-127.

8. Sataloff RT. Physical examination. In: Sataloff RT. Professional voice: the science and art of clinical care. 2. ed. San Diego: Singular Publishing Group, Inc; 1997. p 207-13.
9. Tang JAL, Boliek CA, Rieger JM. Laryngeal and respiratory behavior during pitch change in professional singers. J Voice. 2008; 22(6):622-33.

10. Oliveira IB. Tratado de fonoaudiologia. São Paulo: Roca; 2004.

11. Mendes AP, Brown WSJ, Rothman HB, Sapienza C. Effects of singing training on the speaking voice of voice majors. J Voice. 2004; 18(1):83-9.

12. Iwarsson J. Thomasson M, Sundberg J. Effects of lung volume on the glottal voice source. J Voice. 1998; 12:424-433

13. Thomasson M, Sundberg J. Consistency of inhalatory breathing patterns in professional operatic singers. J Voice. 2001; 15:373-383

14. Bjorkner E. Musical theater and the opera singing: why so different? A study of subglottal pressure, voice source and formant frequency characteristics. J Voice. 2008; 22(5):533-40.

15. Amato RCF. Investigação sobre o fluxo inspiratório na emissão cantada e falada de vogais do Português em cantores líricos brasileiros. Música Hodie Rev Acad Mus. 2007; 7(1):67-82.

16. Ribeiro LR, Hanyama EM. Perfil vocal de coralistas amadores. Rev CEFAC. 2005; 7(2):252-66.

17. Andrada e Silva MA, Duprat A. Tratado de fonoaudiologia. São Paulo: Rocca; 2004.

18. Behlau M. Voz: o livro do especialista. 2. ed. São Paulo: Revinter; 2005. 
19. Thomasson M. Belly-in or belly-out? Effects of inhalatory behaviour and lung volume on voice function in male opera singers. Speech, Music and Hearing, KTH. Stockholm, Sweden TMH-QPSR, KTH. 2003; 45:61-73.

20. Edgar J. Effects of eating on professional and amateur singers for select pulmonary and vocal tasks. J Voice. 2008; (22)6:721-6.

21. Braga A, Pederiva P. Voz e corporeidade segundo a percepção de coralistas. Música Hodie Rev Acad Mus. 2007; 7(1):43-51.
22. Bardin L. História e teoria. In: Bardin L. Análise de conteúdo. Vol 7 Lisboa: Edições Lisboa; 1977. p. $11-46$

23. Sonninen A, Laukkanen AM, Karma K, Hurme P. Evaluation of Support in Singing. Journal of Voice. 2005; 19(2): 223-237.

24. Thomasson M, Sundberg J. Consistency of phonatory breathing patterns in professional operatic singers. J Voice. 1999; 13: 529-541.

DOI: 10.1590/S1516-18462010005000047

RECEBIDO EM: 12/10/2009

APROVADO EM: 21/03/2010

Endereço para correspondencia:

Rua Leandro Dupret, 69

Vila Mariana - São Paulo

CEP: 04025-014

E-mail: studiogava@gmail.com 